\title{
The spatiotemporal variation of reference evapotranspiration and the contribution of its climatic factors in the Loess Plateau, China
}

\author{
Yanzhong $\mathrm{Li}^{1,2,3} \cdot \mathrm{Kang}_{\text {Liang }}{ }^{1,3} \cdot$ Peng Bai ${ }^{1,2,3} \cdot$ Aiqing Feng ${ }^{1,2} \cdot$ \\ Lifang Liu ${ }^{1,2,3}$ - Guotao Dong ${ }^{4}$
}

Received: 5 June 2015 / Accepted: 28 October 2015/Published online: 19 February 2016

(c) Springer-Verlag Berlin Heidelberg 2016

\begin{abstract}
Reference evapotranspiration $\left(\mathrm{ET}_{0}\right)$ is an important parameter of agricultural activity and hydrometeorological studies. In this study, we used the Food and Agriculture Organization Penman-Monteith equation to evaluate $\mathrm{ET}_{0}$, and to investigate the change point of $\mathrm{ET}_{0}$ in the Loess Plateau region from 1960 to 2013. The results showed that a change point was detected at approximately the year 1990 for annual $\mathrm{ET}_{0}$ series from 108 meteorological stations using Cramer's statistical
\end{abstract}

Kang Liang

liangk@igsnrr.ac.cn

Yanzhong Li

liyz_egi@163.com

Peng Bai

baip.11b@igsnrr.ac.cn

Aiqing Feng

aiqingfeng2011@163.com

Lifang Liu

liulifang198160@163.com

Guotao Dong

dongguotao@hky.yearcc.gov.cn

1 Institute of Geographic Sciences and Natural Resources Research, Chinese Academy of Sciences, Beijing, China

2 University of Chinese Academy of Sciences, Beijing, China

3 Key Laboratory of Water Cycle and Related Land Surface Processes, Institute of Geographic Sciences and Natural Resources Research, Chinese Academy of Sciences, 11A, Datun Road, Chaoyang District, Beijing 100101, China

4 Bureau of Hydrology, Yellow River Conservancy Committee, Zhengzhou, China test. The annual $\mathrm{ET}_{0}$ decreased significantly $(p<0.05)$ by $-1.22 \mathrm{~mm} \mathrm{year}^{-1}$ from 1960 to 1990 , especially during the summer months, which contributed the most to the total annual reduction, while it increased significantly ( $p<0.001$ ) by $1.15 \mathrm{~mm} \mathrm{year}^{-1}$ from 1991 to 2013 , with the spring months contributing the most. The $\mathrm{ET}_{0}$ and its trend in the five integrated management divisions of the Loess Plateau have significant spatial heterogeneity. The highest and lowest $\mathrm{ET}_{0}$ were found in the third and fifth divisions from 1960 to 2013. The $\mathrm{ET}_{0}$ decreased significantly in the first division and increased in the fourth divisions (1960-1990 and 1991-2013, respectively). Using differential equations to quantitatively evaluate the contribution of various factors, the wind speed was mostly responsible for the variability in the $\mathrm{ET}_{0}$ trend from 1960 to 1990 , followed by solar radiation and vapor pressure. The positive effect of air temperature on $\mathrm{ET}_{0}$ trend was offset by the other three factors, and the combined effects of the four climatic variables led to the decrease in the $\mathrm{ET}_{0}$ trend. However, the rapidly increasing air temperature became the predominant factor in the change in the $\mathrm{ET}_{0}$ trend after 1990. A spatiotemporal variation of predominant contribution to the $\mathrm{ET}_{0}$ trend was identified. The temperature dominant region changed from the third to the first division for 1960-1990 and 1991-2013. Radiation did not change. Vapor pressure changed from the first to the fourth and the wind speed changed from the forth to the third. This study could contribute to a better understanding of the response of the spatial and temporal variation of $\mathrm{ET}_{0}$ to increased climate change. Additionally, this research also provides scientific support to regional planning and management.

Keywords Reference evapotranspiration - Climate factors contribution - Climate change $\cdot$ Loess Plateau 


\section{Introduction}

Land evapotranspiration (ET) is the nexus of energy and water balance, and can deeply affect the energy redistribution and hydrological cycle (Jung et al. 2010). Because the actual evapotranspiration is difficult to directly estimate, potential evaporation or reference evapotranspiration is generally used. Reference evapotranspiration $\left(\mathrm{ET}_{0}\right)$ is a representation of the environmental demand for evapotranspiration of a particular surface with a "reference crop" (assumed to be of uniform height, with a complete and green plant cover) and soil conditions with sufficient available water (Allen et al. 1998; Srivastava et al. 2015a), $\mathrm{ET}_{0}$ is not only a key component in climatological and hydrological studies, but also irrigation planning and management (Sentelhas et al. 2010; Srivastava et al. 2014). Therefore, reliable estimates of $\mathrm{ET}_{0}$ and its response to the changing climate conditions have become increasingly important (Srivastava et al. 2013; Xu et al. 2006), especially against the background of global warming since the mid-1970s (IPCC 2013). The Penman-Monteith methods recommended by the Food and Agriculture Organization (FAO) are the universal standard for estimation $\mathrm{ET}_{0}$ (Allen et al. 1998; Srivastava et al. 2015b). The Penman-Monteith $\mathrm{ET}_{0}$ equation depends on four climate factors, including temperature $\left(T_{\mathrm{a}}\right)$, solar radiation $\left(R_{\mathrm{s}}\right)$, vapor pressure $(\mathrm{VP})$ and wind speed $(U)$. Global warming and the variation of these climate factors were expected to cause an increase in $\mathrm{ET}_{0}$ (Vautard et al. 2010), but observed pan-evaporation and reference evapotranspiration were both reported to have decreased in many regions of the world (Brutsaert and Parlange 1998; Jhajharia et al. 2012; Liu et al. 2011a; Roderick and Farquhar 2002, 2005), a phenomenon known as the "evaporation paradox" (Brutsaert and Parlange 1998).

The climate factors $T_{\mathrm{a}}, R_{\mathrm{s}}, \mathrm{VP}$ and $U 2$ were employed to explain the decrease trend in pan-evaporation and/or $\mathrm{ET}_{0}$. Until now, the major interpretation of this phenomenon was the decrease in wind speed in regions, such as the Northern Hemisphere (Vautard et al. 2010), Canada (Wan et al. 2010), German (Bormann 2011), Australia (Roderick et al. 2007), the Hai River (Tang et al. 2011),the Yellow River (Liu et al. 2010b), the Tibetan Plateau (Liu et al. 2011b), arid/semi-arid/semi-humid regions of China (Zhang et al. 2013) and the whole of China (Liu et al. 2010a, 2011a). Solar radiation (Wang et al. 2007; Xu et al. 2006; Zhang et al. 2013), vapor pressure and temperature (Golubev et al. 2001; Tabari et al. 2011) have also been used to explain the decrease in $\mathrm{ET}_{0}$. However, due to regional complexity, the climatic factors on a regional scale showed discrepancies with global climate change, which could explain the difference in the regional $\mathrm{ET}_{0}$ trend and the predominant climate factors. Some studies have documented that recently, various increasing trends in $\mathrm{ET}_{0}$ associated with the variation of climate factors in many regions with widely different climates were evident. In Greece, a changing point in the $\mathrm{ET}_{0}$ trend was found to occur approximately during the 1980s. $\mathrm{ET}_{0}$ showed a declining trend before the early 1980s, associated with a downward trend in annual precipitation and the number of rainy days, and then increased significantly due to the strengthening of solar radiation (Papaioannou et al. 2011). The change point was also detected in approximately 1993 in the Wei River basin of China, when an abrupt change in the air temperature and the relative humidity were also detected (Zuo et al. 2012). In the arid region of China, the $\mathrm{ET}_{0}$ trend changed from negative during 1960-1993 to positive during 1993-2010, due to a decrease in wind speed before 1993 and an increase in temperature and wind speed after 1993 (Liu and Zhang 2013). In the Poyang Lake Basin of China, a decrease in temperature during 1959-1973 and a decrease in wind speed and solar radiation during 1974-1995 was mostly responsible for the pan-evaporation decrease; subsequently, significant increases in wind speed and air temperature were mostly responsible for an increase in pan-evaporation from 1996 to 2012 (Zhang et al. 2014). The entire trend in $\mathrm{ET}_{0}$ in China was analyzed from 1960 to 2007, indicating that a significant decrease in wind speed and solar radiation offset the effect of increasing temperature and led to a decrease in $\mathrm{ET}_{0}$ before 1992; therefore, a serious increase in was mostly responsible for an increase in $\mathrm{ET}_{0}$ from 1992 to 2007 (Liu et al. 2011a).The detection of the changing point and quantitative analysis of the contribution of major climate factors to $\mathrm{ET}_{0}$ was significant for a deep understanding of $\mathrm{ET}_{0}$, as well as of the hydrological process and the response to global and regional climate change.

The Loess Plateau, located in the transition zone between the semi-arid and semi-humid regions of China, is sensitive to climate change (Jinbai et al. 2014; Wang et al. 2012) and vulnerable to human activity (Zhang et al. 2007a). Evapotranspiration, which mostly controlled the water balance, had a great influence on hydrological processes and changed significantly in response to the changing conditions (Huang et al. 2003; Li et al. 2014a; Liu et al. 2012b, 2013; Zhang et al. 2008a). A change in $\mathrm{ET}_{0}$ would have a significant impact on the variability in evapotranspiration. Consequently, understanding the variation of $\mathrm{ET}_{0}$ is a vital component of hydrological studies in Loess Plateau. Several studies have documented the $\mathrm{ET}_{0}$ at the Loess Plateau ( $\mathrm{Li}$ et al. 2012; Zhao et al. 2014). However, few studies have analyzed the spatiotemporal variation in the trend $\mathrm{ET}_{0}$ and its contribution to climatic factors in the Loess Plateau, especially in the various 
integrated management regions. Quantifying and analyzing the magnitude and spatial pattern of $\mathrm{ET}_{0}$ trends and its reasons for these trends not only enhances our understanding of regional responses to climate change, but is also essential for formulating water resource management and irrigation strategies.

We focused on the spatiotemporal variation of $\mathrm{ET}_{0}$ in the Loess Plateau in this study. Our objectives were (1) to detect the changing point of $\mathrm{ET}_{0}$ from 1960 to 2013, (2) to investigate the spatial and temporal variation of $\mathrm{ET}_{0}$ and its trend, as affected by solar radiation, wind speed, vapor pressure and temperature, (3) and to explore the contribution of these climatic factors to $\mathrm{ET}_{0}$ trend in the various integrated management regions of the Loess Plateau.

\section{Study area and data}

\section{Study area}

The Loess Plateau $\left(33^{\circ} 43^{\prime} \mathrm{N}-41^{\circ} 16^{\prime} \mathrm{N}, 100^{\circ} 54^{\prime} \mathrm{E}-114^{\circ} 33^{\prime}\right.$ $\mathrm{E})$ is located in the middle reaches of the Yellow River basin in China (Fig. 1), which covers about $6.2 \times 10^{5} \mathrm{~km}^{2}$ and accounts for approximately $6.7 \%$ of the total land area of China. Most of the Loess Plateau belongs to semi-humid and semi-arid climate with average annual precipitation ranging from $200 \mathrm{~mm}$ in the northwest to nearly $750 \mathrm{~mm}$ in the southeast. The rainy season, from June to September, accounts for approximately $65 \%$ of the total precipitation, most of which is in the form of frequent high intensity storms. The northwestern Loess Plateau is sandy, while a series of complex geomorphic landform in the southeast, such as plateau, ridges, mounds and gullies, dominate the area, which is characterized by loess-paleosol soil with an average depth in excess of $100 \mathrm{~mm}$. Silt clay-loam texture are common with sandy texture in the northwest and more clay in the southeast (Wu and Yang 1998). Vegetation cover is distributed with forest, forest-steppe, typicalsteppe and desert-steppe zones from southeast to northwest, and the land use is predominantly cultivated croplands and improved grassland.

Based on the integrated management division system, the Loess Plateau was divided into five integrated management divisions: (1) the southeast river valley and rocky mountain division, (2) the key soil and water conservation division, (3) the northwest windy and sandy division, (4) the central Gansu hilly and mountainous division, (5) and the east Qinghai division [Integrated Survey Team of Chinese Academy of Sciences (CAS) of the Loess Plateau 1992; Li et al. 2010; Wang et al. 2011].

\section{Meteorological data}

Daily meteorological records from 108 national meteorological stations from 1960 to 2013 from the National Climatic Center of China Meteorological Administrator were used in this study (Fig. 1). Crop reference evapotranspiration was calculated based on the mean values of the daily maximum, minimum and air temperature $\left(T_{\max }, T_{\min }\right.$ and $T_{\mathrm{a}}$ ) at $2 \mathrm{~m}$ height, wind speed measured at $10 \mathrm{~m}$ height, vapor pressure (VP) at $2 \mathrm{~m}$ height and sunshine duration (Allen et al. 1998). The observed sunshine duration in a day was defined as the number of hours in which the direct solar irradiance exceeded $120 \mathrm{~W} \mathrm{~m}^{-2}$ (WMO 1996). Wind speed was adjusted to $2 \mathrm{~m}$ height (U2) using wind profile relationship (Allen et al. 1998).
Fig. 1 The sketch map of the study area. The black dot line shows the five integrated management divisions of the Loess Plateau

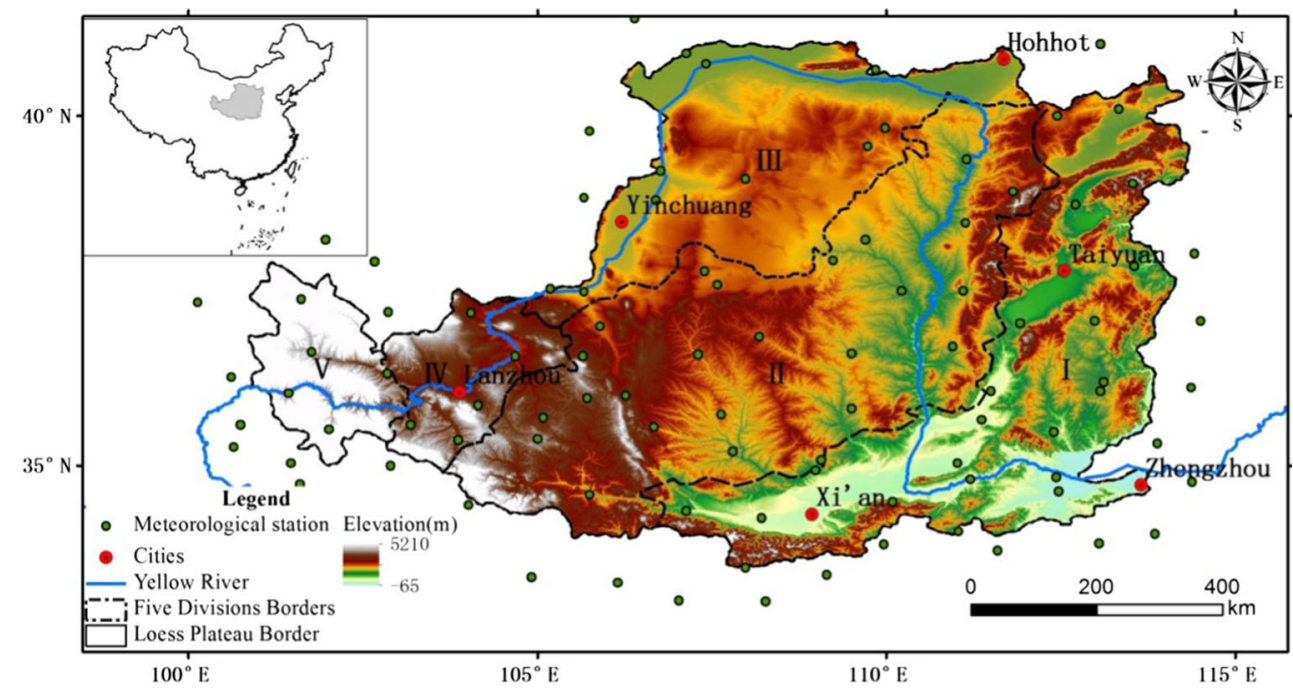




\section{Methodology}

\section{Statistical analysis}

Cramer's test has shown good performance in detecting the stability of a record by comparing the overall mean of the entire record and the means of certain parts of the record (TÜRkeS 1996). The Cramer's test statistic $t_{k}$ is calculated as:

$t_{k}=\sqrt{\frac{n(N-2)}{N-n\left(1+\tau_{k}^{2}\right)}} \times \tau_{k}$

$\tau_{k}=\frac{\bar{x}_{k}}{s}, \bar{x}_{k}=\frac{1}{n} \sum_{i=k+1}^{k+n} x_{i}, \bar{x}=\frac{1}{N} \sum_{i=1}^{N} x_{i}$

$\bar{x}$ and $s$ are the mean and standard deviation, respectively, for the entire period of $N$ years, and $\bar{x}$ is the mean of the sub-period of the $n$th year to be compared with $\bar{x}$. The test statistic $t_{k}$ assumes Student's $t$ distribution with $(N-2)$ degrees of freedom. The null hypothesis is that no significant difference exists between the mean of the sub-period and that the mean of the entire period and is rejected in a two-tailed test for large values of $\left|t_{k}\right|$.

The rank-based non-parametric Mann-Kendall statistical test (Kendall 1948; Liu and Zhang 2013) is commonly used for trend detected due to its robustness for non-normally distributed data, which are frequently encountered in hydro-climatic time-series (Liu et al. 2011a, 2012a; Zhang et al. 2013; Zheng et al. 2009). Assuming a normal distribution at the significant level of $p=0.05$, a positive Mann-Kendal statistic $Z$ larger than 1.96 indicates an significant increasing trend, while a negative $Z$ lower than -1.96 indicates a significant decreasing trend. Critical $Z$ values of $\pm 1.64, \pm 2.58$ and \pm 3.29 were used for the probabilities of $p=0.1,0.01$ and 0.001 , respectively.

Climate factors difference between 1960-1990 and 1991-2013 were analyzed using the one-way analysis of variance (ANOVA), least significant difference (LSD) test and the $F$ test $(p<0.05)$ in SPSS 19.0 (Dai et al. 2013).

\section{Calculation of $\mathbf{E T}_{\mathbf{0}}$}

The FAO Penman-Monteith $\mathrm{ET}_{0}$ model can calculate the theoretical values because the model does not consider actual surface soil type and water availability. The model provides a standard with which to compare the evapotranspiration capability under various climatic conditions, and it has been successfully applied at scales from a single basin to all of China (Chen et al. 2006; Gao et al. 2006; Heydari et al. 2014; Meng and Mo 2012; Zhang et al. 2007b; Zheng et al. 2009).The Penman-Monteith $\mathrm{ET}_{0}$
(Allen et al. 1998) is calculated at daily scale according the following equation:

$\mathrm{ET}_{0}=\frac{0.408 \Delta\left(R_{\mathrm{n}}-G\right)+\gamma \frac{900}{T_{\mathrm{a}}+273} u_{2} \mathrm{VPD}}{\Delta+\gamma\left(1+0.34 u_{2}\right)}$

where $R_{\mathrm{n}}$ is the net radiation at the canopy surface $\left(\mathrm{MJ} \mathrm{m}^{-2} \mathrm{day}^{-1}\right), \quad G$ is the soil heat flux density $\left(\mathrm{MJ} \mathrm{m}^{-2}\right.$ day $^{-1}$ ) calculated by the difference of mean daily air temperature between two continuous days, $T_{\mathrm{a}}$ is the mean daily air temperature at $2 \mathrm{~m}$ height $\left({ }^{\circ} \mathrm{C}\right), U 2$ is the wind speed at $2 \mathrm{~m}$ height $\left(\mathrm{m} \mathrm{s}^{-1}\right)$, VPD is the vapor pressure deficit $(\mathrm{kPa})$ (the difference between saturated and actual vapor pressure), $\Delta$ is the slope of saturated vapor pressure in relation to air temperature $\left(\mathrm{kPa}^{\circ} \mathrm{C}^{-1}\right)$, and $\gamma$ is the psychrometric constant $\left(\mathrm{kPa}{ }^{\circ} \mathrm{C}^{-1}\right) . R_{\mathrm{n}}$ is a function of solar radiation, which can be estimated by the difference between the net shortwave radiation $\left(R_{\mathrm{ns}}\right)$ and the net longwave radiation $\left(R_{\mathrm{nl}}\right) . R_{\mathrm{S}}$ can be estimated as:

$R_{\mathrm{s}}=\left(a_{\mathrm{s}}+b_{\mathrm{s}} \frac{n}{N}\right) R_{\mathrm{a}}$

where $n$ is the actual duration of sunshine (h), $N$ is the maximum possible duration of sunshine or daylight hours (h) $\left(n / N\right.$ is the relative sunshine duration), and $R_{\mathrm{a}}$ is the extraterrestrial radiation intensity $\left(\mathrm{MJ} \mathrm{m}^{-2} \mathrm{day}^{-1}\right)$. The coefficients $a_{\mathrm{s}}$ and $b_{\mathrm{s}}$ were estimated by an optimized method for solar radiation (Liu et al. 2012a; Zeng et al. 2008), which can improve the precision of the $\mathrm{ET}_{0}$ estimation.

\section{Attribution analysis of change in $\mathbf{E T}_{\mathbf{0}}$}

For a function $y=f\left(x_{1}, x_{2}, \ldots\right)$, the variation of the dependent variable $y$ can be expressed by the differential equation as:

$\mathrm{d} y=\sum \frac{\partial f}{\partial x_{i}} \mathrm{~d} x_{i}=\sum f_{i}^{\prime} \mathrm{d} x_{i}$,

where $x_{i}$ is the $i$ th independent variable and $f_{i}=\partial f / \partial x_{i}$. Moreover, as y varies with time t, we can rewrite Eq. (5) as

$\frac{\mathrm{d} y}{\mathrm{~d} t}=\sum \frac{\partial f}{\partial x_{i}} \frac{\mathrm{d} x_{i}}{\mathrm{~d} t}=\sum f_{i}^{\prime} \frac{\mathrm{d} x_{i}}{\mathrm{~d} t}$

Therefore, according to the Penman-Monteith formula and Eq. (6), the contribution of the change in a climate variable to the $\mathrm{ET}_{0}$ trend can be approximately estimated as:

$\frac{\mathrm{dET}_{0}}{\mathrm{~d} t}=\frac{\partial \mathrm{ET}_{0}}{\partial R_{\mathrm{S}}} \frac{\mathrm{d} R_{s}}{\mathrm{~d} t}+\frac{\partial \mathrm{ET}_{0}}{\partial T_{a}} \frac{v T_{a}}{\mathrm{~d} t}+\frac{\partial \mathrm{ET}_{0}}{\partial U} \frac{v U}{\mathrm{~d} t}+\frac{\partial \mathrm{ET}_{0}}{\partial \mathrm{VP}} \frac{\mathrm{dVP}}{\mathrm{d} t}+\varepsilon$

or simplified as:

$C\left(\mathrm{ET}_{0}\right)=$ Cr $\_T_{\mathrm{a}}+\mathrm{Cr} \_R_{\mathrm{s}}+\mathrm{Cr} \_\mathrm{VP}+\mathrm{Cr} \_U+\varepsilon$ 
where $\mathrm{Cr}_{-} T_{\mathrm{a}}, \mathrm{Cr} R_{\mathrm{s}}, \mathrm{Cr}_{-} \mathrm{VP}, \mathrm{Cr} \_U$ are the individual contributions to the long-term trend in $\mathrm{ET}_{0}$ due to a change in $R_{\mathrm{s}}, T_{\mathrm{a}}, U$ and $\mathrm{VP}$, respectively. $C\left(\mathrm{ET}_{0}\right)$ is the sum of the contribution of changes in $R_{\mathrm{S}}, T_{\mathrm{a}}, U$ and VP to the trend in $\mathrm{ET}_{0} . \varepsilon$ is the error between $C\left(\mathrm{ET}_{0}\right)$ and $\mathrm{ET}_{0}$ trend detected by linear regression $L\left(\mathrm{ET}_{0}\right)$. The differential equation method had been typically used to conduct an attribution analysis of the change in $\mathrm{ET}_{0}$ (Liu et al. 2011a, b; Liu and Zhang 2013; Roderick et al. 2007; Zhang et al. 2013; Zheng et al. 2009).

\section{Data spatialization}

Many algorithms are available to spatially interpolate data, and a few of these have been primarily used to interpolate meteorological and climatic data sets (McVicar et al. 2007). In this study, Kriging (Xu et al. 2006), Spline (New et al. 2000) and inverse distance weighted (IDW) (Lu and Wong 2008), which were regarded as the most popular methods to interpolate data, were tested for interpolation of the annual $\mathrm{ET}_{0}$. To determine which interpolation method gave the best performance, cross validation (Lloyd 2005) was chosen to test the performance of the three methods using the monthly $\mathrm{ET}_{0}$ value of 108 stations in the Loess Plateau. The steps were as follows: 20 stations were randomly selected and removed, and then their values were interpolated using the values of the remaining 88 stations by each of three methods. Finally, the absolute error (ABS), relative error (REE), $R^{2}$ coefficient and root mean square (RMS, Eq. 9) between the estimated and original $\mathrm{ET}_{0}$ values were calculated. The test results are listed in Table 1. The best results were obtained from the IDW method according to the cross-validation tests, which had also been used successfully for interpolating $\mathrm{ET}_{0}$ and climate variables by other researchers (Liu et al. 2012a; Qian et al. 2006; Zhang et al. 2013), so the IDW method was selected for interpolating annual $\mathrm{ET}_{0}$ and climatic variables at 108 stations to $5 \mathrm{~km}$ resolution grid across the entire Loess Plateau.

$\mathrm{RMS}=\sqrt{\frac{1}{n} \sum_{i=1}^{n}\left(z_{i, \mathrm{act}}-z_{i, \mathrm{est}}\right)^{2}}$

Table 1 Cross validation of different methods for interpolating $\mathrm{ET}_{0}$ $(n=4800)$

\begin{tabular}{lllr}
\hline Methods & Kriging & IDW & Spline \\
\hline ABS $(\mathrm{mm})$ & 5.91 & 5.84 & 6.96 \\
REE $(\%)$ & 9.32 & 9.22 & 11.21 \\
$R^{2}$ & 0.97 & 0.97 & 0.95 \\
RMS & 7.97 & 7.86 & 9.31 \\
\hline
\end{tabular}

\section{Results}

\section{Variation of $\mathbf{E T}_{\mathbf{0}}$}

Temporal variation of $E T_{O}$

To obtain the temporal variation of $\mathrm{ET}_{0}$, the meteorological data from the Loess Plateau during 1960-2013 were analyzed, and the long-term variation of annual $\mathrm{ET}_{0}$ is plotted in Fig. 2a. The changing point of the annual $\mathrm{ET}_{0}$ series was detected at approximately 1990 by Cramer's test (Fig. 2b). During the period from 1960 to 1990 , the annual $\mathrm{ET}_{0}$ decreased significantly $(p<0.05)$ by $-1.22 \mathrm{~mm}_{\text {year }}{ }^{-1}$, with a range of $792.31-959.35 \mathrm{~mm}$; the mean $\mathrm{ET}_{0}$ was $892.51 \mathrm{~mm}$ and the standard deviation was 39.12. However, during the period of 1990 to 2013, the $\mathrm{ET}_{0}$ increased significantly $(p<0.01)$ by $1.15 \mathrm{~mm}$ year $^{-1}$, with a range of $953.79-839.66 \mathrm{~mm}$; the mean $\mathrm{ET}_{0}$ was $906.92 \mathrm{~mm}$, and the standard deviation was $30.93 \mathrm{~mm}$ (Table 2). However, for the whole study time series from 1960 to 2013, a nonsignificant $(p>0.05)$ increased in the annual $\mathrm{ET}_{0}$ of $0.28 \mathrm{~mm}$ year $^{-1}$ was found, which was different from other regions in China (Liu et al. 2012a) which indicated, to some extent, that the "pan evaporation paradox" may disappear in the Loess Plateau (Liu et al. 2011a, 2012a; Liu and Zhang 2013).

The variation of $\mathrm{ET}_{0}$ and its trends has obvious seasonal characteristics. Averaged over the period of 1960-2013, in summer, the $\mathrm{ET}_{0}$ comprises approximately $40 \%$ of the annual reference evapotranspiration (approximately $358 \mathrm{~mm}$ ), followed by spring (approximately $280 \mathrm{~mm}$, which is approximately $30 \%$ of the annual value), and the lowest value of $92.27 \mathrm{~mm}$ was found for winter (Table 3). A comparison of the two periods before and after 1990 indicated that the $\mathrm{ET}_{0}$ in spring showed a distinct temporal difference, which was lowest in the summertime. The seasonal trend of $\mathrm{ET}_{0}$ also showed significant differences between 1960-1990 and 1991-2013. Before 1990, all seasons except autumn showed a decreasing trend. The largest statistically significant $(p<0.01) \mathrm{ET}_{0}$ decreasing trend $\left(-0.86 \mathrm{~mm} \mathrm{year}^{-2}\right)$ was found in summer, followed by non-significant trends $(p>0.05)$ in spring and winter. In contrast, all of the seasonal trends of $\mathrm{ET}_{0}$ were positive except during autumn. Spring showed the greatest significant $(p<0.05)$ increase, followed by summer and winter. Overall we can conclude that the $\mathrm{ET}_{0}$ in summer was much greater than during the other seasons and had the least variation in the three periods. In addition, for the four seasons, summer showed the greatest decreases in $\mathrm{ET}_{0}$ during 1960-1990, while later, the increasing trend of $\mathrm{ET}_{0}$ in spring played a more important role than that during the other seasons in determining the overall trend of the $\mathrm{ET}_{0}$. 

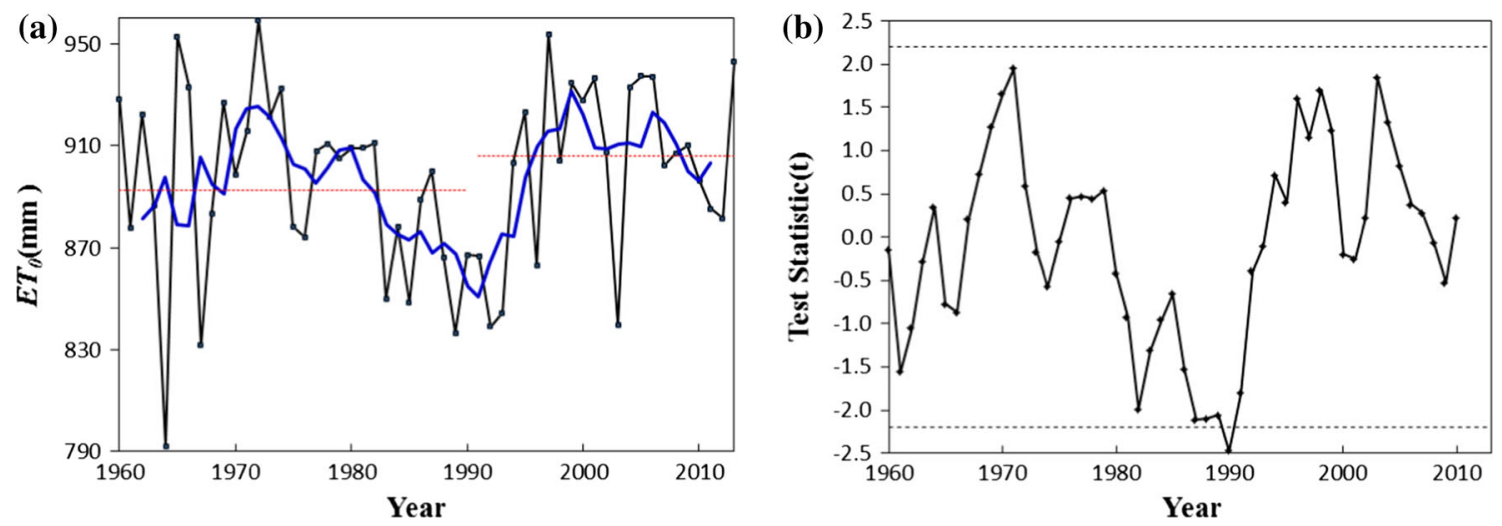

Fig. 2 Changes of $\operatorname{ET}_{0}(\mathbf{a})$ and Cramer's test result (b) for detecting changing year. The blue and red lines (a) show the 5 year moving average and the mean value for the two periods. The black dot line (b) shows the threshold value

Table 2 The trend, mean and standard deviation (SD) of $\mathrm{ET}_{0}$ for different periods

\begin{tabular}{lcll}
\hline Period & Trend $\mathrm{ET}_{0}\left(\mathrm{~mm} \mathrm{year}^{-2}\right)$ & Mean $\mathrm{ET}_{0}(\mathrm{~mm})$ & $\mathrm{SD}$ \\
\hline $1960-1990$ & $-1.22^{*}$ & 892.51 & 39.12 \\
$1991-2013$ & $1.15^{* *}$ & 906.92 & 30.93 \\
$1960-2013$ & 0.28 & 898.66 & 36.25 \\
\hline
\end{tabular}

Slope is the linear trend estimated by the linear regression. $* p<0.05, * * p<0.01$

\section{Spatial variation of $E T_{0}$}

The spatial distribution of $\mathrm{ET}_{0}$ and its trends is shown in Fig. 3. The spatial distribution pattern of $\mathrm{ET}_{0}$ was similar during three periods but without significant differences. A higher $\mathrm{ET}_{0}$ was found for the northwest Loess Plateau, while lower values were evident in the southwest and northeast areas (A1-A3). In the five integrated management divisions, the third division had the largest $\mathrm{ET}_{0}$ of approximately $993 \mathrm{~mm}$ year $^{-1}$, while the smallest value of approximately $821 \mathrm{~mm} \mathrm{year}^{-1}$ was found in the fifth division and no significant differences were seen in the three periods (Table 4). However, the $\mathrm{ET}_{0}$ in the first, second and forth divisions differed substantially before and after 1990, increasing by $6.8,16.8$ and $21.6 \mathrm{~mm}$ for the three periods, respectively.

There was significant spatial heterogeneity in the $\mathrm{ET}_{0}$ trend between 1960-1990 and 1991-2013 (Fig. 3B1-B3). All regions showed a decreasing trend during 1960 to 1990, while an increasing trend was evident after 1990, except for the third division. Figure 3B1 shows that most of the Loess Plateau had a decreasing trend from 1960 to 1990, especially significant during the first division $\left(-2.95 \mathrm{~mm}\right.$ year $\left.{ }^{-2}\right)$ and located in the plain area affected mostly by human activity, while the third division had the least decreasing trend $\left(-0.24 \mathrm{~mm}\right.$ year $\left.^{-2}\right)$, located in the northwest Loess Plateau. From 1991 to 2013, the spatial distribution pattern was reversed; most of the area had an increasing trends expect for the northwest region (i.e., the third division, with value $-1.96 \mathrm{~mm}_{\text {year }}{ }^{-2}$ ). The second and forth divisions showed significant increases (1.02 and $3.54 \mathrm{~mm}$ year $^{-2}$, respectively), followed by the first and fifth divisions (both $0.9 \mathrm{~mm} \mathrm{year}^{-2}$ ).

\section{Attribution analyses of change in $\mathbf{E T}_{0}$}

\section{Climatic factor contribution to $E T_{O}$ trends}

The principal weather parameters affecting $\mathrm{ET}_{0}$ are air temperature, radiation, vapor pressure and wind speed (Allen et al. 1998). The differential Eq. (5) provides an effective method to quantitatively estimate the contribution of climatic factor changes to the long-term $\mathrm{ET}_{0}$ trend. Comparing the calculated (Fig. 4a) and the detected $\mathrm{ET}_{0}$ trends (Fig. 4b) by linear regression from 1991 to 2013 using the 108 stations, the square of correlation coefficient was as high as 0.99 , which indicates that the differential equation method has excellent performance for the detection of contribution to the trends in the Loess Plateau. During 1960-1990 and 1991-2013, the absolute error between $\mathrm{Cr}_{-} \mathrm{ET}_{0}$ and $\mathrm{LR}_{-} \mathrm{ET}_{0}$ was 0.11 and $0.06 \mathrm{~mm} \mathrm{year}^{-2}$, with a relative error of -9.42 and $5.34 \%$, respectively (Table 5). This satisfactory agreement between $\mathrm{Cr}_{-} \mathrm{ET}_{0}$ and $\mathrm{LR}_{-} \mathrm{ET}_{0}$ suggested that it was a reasonable method for the estimation of the contributions of the individual climatic factors to the long-term trends in $\mathrm{ET}_{0}$ using Eq. (5).

During 1960-1990, an increasing $T_{\mathrm{a}}$ led to an increase in $\mathrm{ET}_{0}$ of $0.06 \mathrm{~mm}$ year $^{-2}$, while changes in radiation, vapor pressure and wind speed led to a decrease in $\mathrm{ET}_{0}$ of -0.3 , -0.03 and $-0.84 \mathrm{~mm} \mathrm{year}^{-2}$, respectively (Table 5). The combined effects of the four climatic factors resulted in an 
Table 3 Seasonal variation of $\mathrm{ET}_{0}$ and its trends

\begin{tabular}{lllll}
\hline Seasons & Spring & Summer & Autumn & Winter \\
\hline $1960-1990$ & $274.12(-0.25)$ & $358.14\left(-0.86^{* *}\right)$ & $168.4(0.13)$ & $91.85(-0.25)$ \\
$1991-2013$ & $283.32\left(1.35^{*}\right)$ & $358.79(0.16)$ & $171.96(-0.35)$ & $92.84(0.01)$ \\
$1960-2013$ & $278.04(0.31)$ & $358.42(-0.12)$ & $169.92(0.10)$ & $92.27(-0.02)$ \\
\hline
\end{tabular}

Spring includes March, April and May, summer is from June to August, autumn is from September to November, and winter is from December to February. $* p<0.05, * * p<0.01$
Fig. 3 Spatial distribution of $\mathrm{ET}_{0}(A 1-A 3)$ and $\mathrm{ET}_{0}$ trends (B1-B3) during different periods. No trend changes of $0 \mathrm{~mm}$ per year per year are shown in grey to enhance clarity
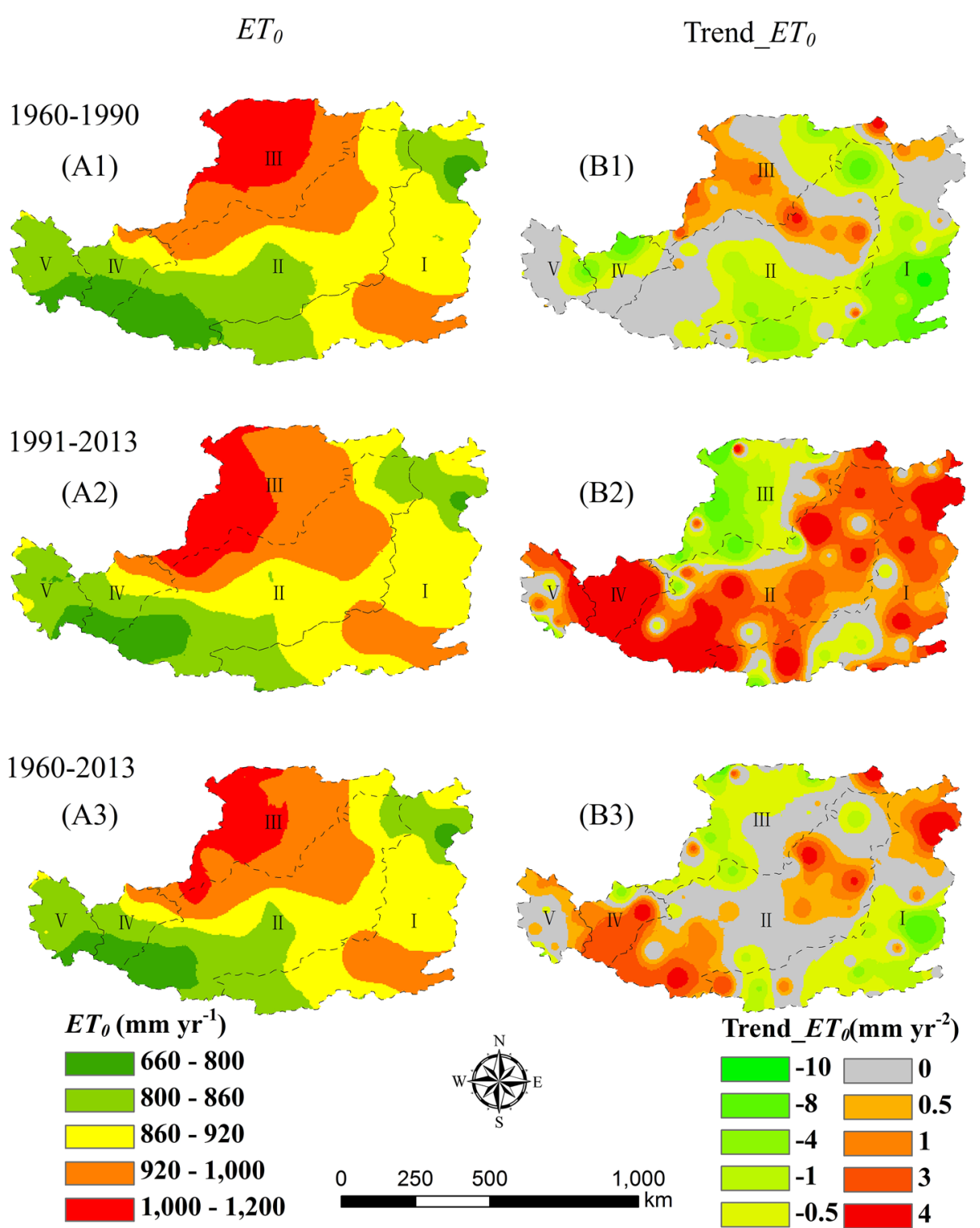

$\mathrm{ET}_{0}$ decrease of $1.11 \mathrm{~mm}$ year $^{-2}$. It is obvious that the wind speed was the predominant factor for the decrease in $\mathrm{ET}_{0}$, followed by solar radiation and vapor pressure. Although the temperature showed an increasing effect on $\mathrm{ET}_{0}$, this effect was offset by changes in solar radiation, vapor pressure and wind speed. During 1991-2013, an increase in temperature and vapor pressure led to an increase in $\mathrm{ET}_{0}$ of 19.4 and $0.42 \mathrm{~mm}_{\text {year }}{ }^{-2}$, respectively, and changes in solar radiation and wind speed led to decrease in $\mathrm{ET}_{0}$ of -0.33 and $-0.95 \mathrm{~mm}_{\text {year }}{ }^{-2}$, respectively. The combined effects of the four climatic variables resulted in an increase in $\mathrm{ET}_{0}$ of $1.09 \mathrm{~mm} \mathrm{year}^{-2}$. It was clear that the decreasing wind speed and solar radiation could not offset the effect of the increasing $T_{\mathrm{a}}$ and vapor 
Table 4 Comparison of $\mathrm{ET}_{0}\left(\mathrm{~mm} \mathrm{year}^{-1}\right)$ and the trends in $\mathrm{ET}_{0}$ $\left(\mathrm{mm}\right.$ year $\left.^{-2}\right)$ in the five divisions for different periods

\begin{tabular}{llll}
\hline Divisions & $1960-1990$ & $1991-2013$ & $1960-2013$ \\
\hline I & $879.64(\mathbf{- 2 . 9 5})$ & $886.44(0.98)$ & $883.04(-0.97)$ \\
II & $875.08(-1.08)$ & $891.88(1.02)$ & $883.48(-0.03)$ \\
III & $993.27(-0.24)$ & $993.00(-1.96)$ & $993.13(-1.10)$ \\
IV & $833.35(-2.10)$ & $854.98(\mathbf{3 . 5 4})$ & $844.17(0.73)$ \\
V & $821.79(-1.11)$ & $821.93(0.98)$ & $821.86(-0.07)$ \\
\hline
\end{tabular}

The bold value in bracket indicates change significantly $(p<0.01)$

pressure; consequently, $\mathrm{ET}_{0}$ has shown an increasing trend since 1990. As mentioned above, we can conclude that significant changes in wind speed was the most important factor affecting the decrease in $\mathrm{ET}_{0}$ before 1990; afterwards, temperature became the most important factor.

\section{Spatial pattern of climate factors contribution to $\mathbf{E T}_{\mathbf{0}}$ trend}

Figure 5 shows the spatial pattern of the contribution of climatic factors to $\mathrm{ET}_{0}$ trends during 1960-2013 for the five divisions in the Loess Plateau. A distinct spatiotemporal variation in the contributions during the two successive periods (1960-1990 vs. 1991-2013) in the five divisions was evident.

Temperature contributed most greatly to the $\mathrm{ET}_{0}$ trend of $0.57 \mathrm{~mm} \mathrm{year}^{-2}$ from 1960 to 1990 in the third division, located in the northwest parts of Loess Plateau, followed by the second and fifth divisions with values of 0.13 and $0.11 \mathrm{~mm}$ year $^{-2}$, respectively (Fig. 5A1; Table 6). These three divisions all led to an increase in $\mathrm{ET}_{0}$, while the first and fourth contributed negatively, leading to an decrease in $\mathrm{ET}_{0}$ of -0.22 and $-0.12 \mathrm{~mm}_{\text {year }}{ }^{-2}$; the combined effect of the five divisions resulted in a slight increase in $\mathrm{ET}_{0}$. In contrast, the $T_{\mathrm{a}}$ contribution to the average $\mathrm{ET}_{0}$ trend from 1991 to 2013 was positive in all the five divisions, varying from 1.36 in the fifth division to $2.91 \mathrm{~mm} \mathrm{year}^{-2}$ in the first division (Fig. 5A2; Table 6). It is clear that all of the divisions had led to significant increases in $\mathrm{ET}_{0}$, especially the first division. A negative contribution from solar radiation to the $\mathrm{ET}_{0}$ trend was observed in all five divisions and during both periods. The predominant regional contribution was in the first division (-0.66 $\mathrm{mm} \mathrm{year}^{-2}$ ) from 1960 to 1990 , followed by the second and fifth division $\left(-0.33\right.$ and $-0.23 \mathrm{~mm} \mathrm{year}^{-2}$, respectively) (Fig. 5B1; Table 6). After 1990, the predominant regional contribution was still found in the first division $\left(-0.70 \mathrm{~mm} \mathrm{year}^{-2}\right)$, and the effect was even stronger than in the former period. The least regional contribution was found in the fifth division, leading only to a decrease in $\mathrm{ET}_{0}$ of $-0.06 \mathrm{~mm} \mathrm{year}^{-2}$ (Fig. 5B2; Table 6). The negative contribution of vapor pressure in the first and forth division to the $\mathrm{ET}_{0}$ trend had values of -1.04 and $-0.17 \mathrm{~mm} \mathrm{year}^{-2}$, respectively (Fig. 5C1; Table 6), while the other regions showed positive effects from 1960 to 1990. The combined effect in the five divisions contributed to a slight decrease in $\mathrm{ET}_{0}$. From 1991 to 2013, the contribution was greatest in the third region $\left(0.58 \mathrm{~mm}_{\text {year }}{ }^{-2}\right)$. Furthermore, except for the
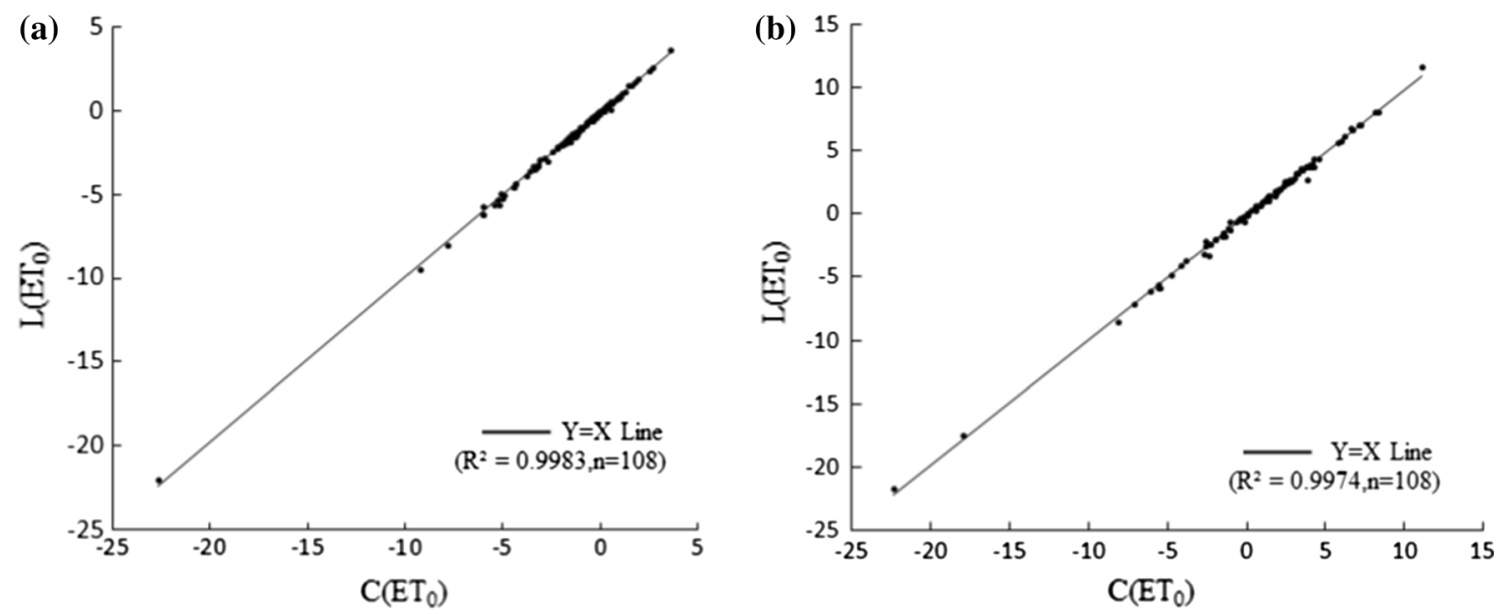

Fig. 4 Comparison between the calculated $\mathrm{ET}_{0}$ trend $C\left(\mathrm{ET}_{0}\right)$ and the detected $\mathrm{ET}_{0}$ trend $L\left(\mathrm{ET}_{0}\right)$ by linear regression for period $1960-1990$ (a) and 1991-2013 (b)

Table 5 Contributions of meteorological variables to the long- term trends in $\mathrm{ET}_{0}$

\begin{tabular}{lllrrrrr}
\hline Period & Cr_T & Cr_Rs & Cr_VP & Cr_U2 & Cr_ET $_{0}$ & LR_ET $_{0}$ & $\rho(\varepsilon)(\%)$ \\
\hline $1960-1990$ & 0.06 & -0.30 & -0.03 & $-\mathbf{0 . 8 4}$ & -1.11 & -1.22 & -9.42 \\
$1991-2013$ & $\mathbf{1 . 9 4}$ & -0.33 & 0.42 & -0.95 & 1.09 & 1.15 & 5.34 \\
\hline
\end{tabular}


Fig. 5 Spatial pattern of the contribution of climatic factors to $\mathrm{ET}_{0}$ trends. Small contributions are shown in grey to enhance clarity

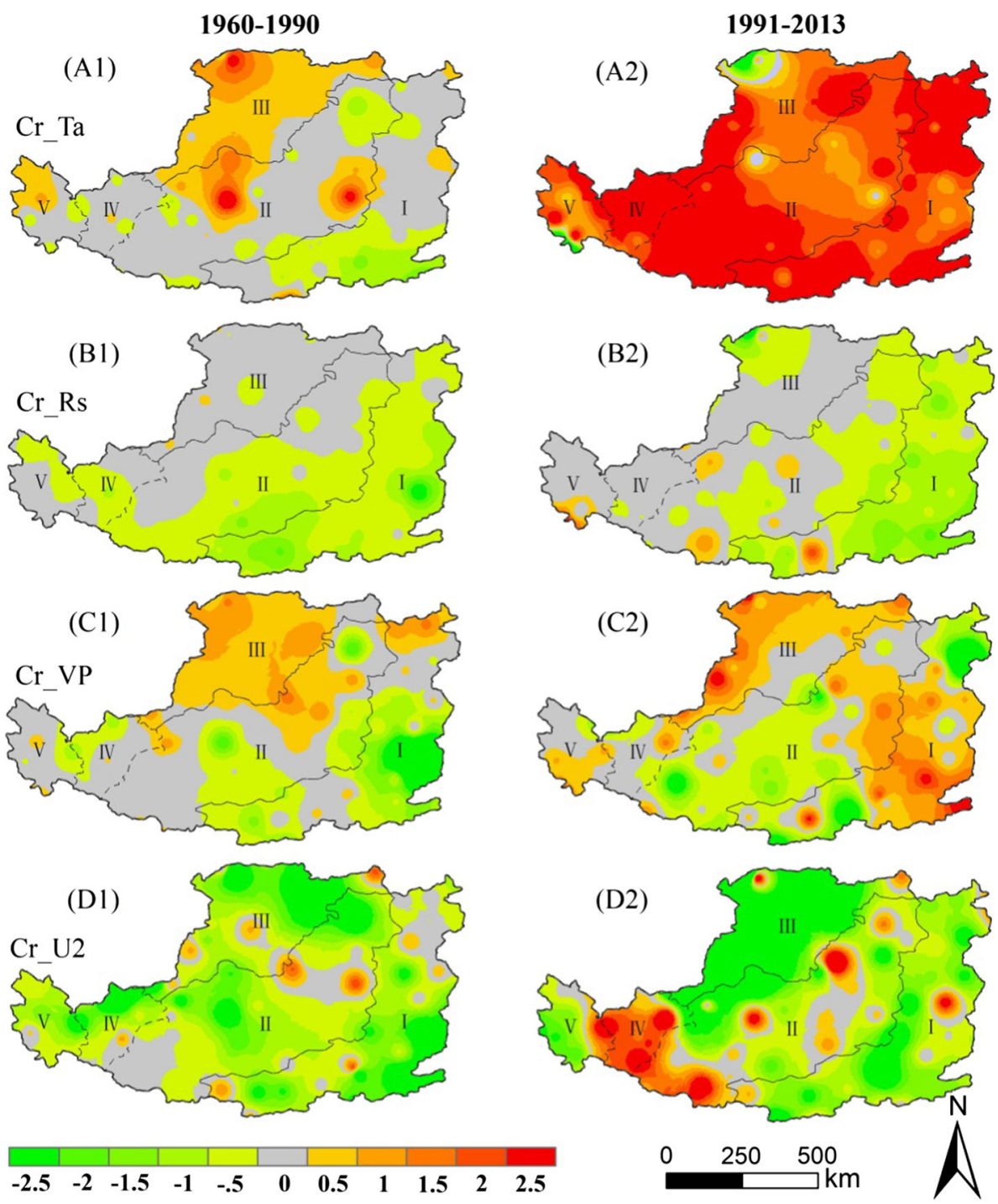

Table 6 Climate factor contributions to $\mathrm{ET}_{0}$ trend in five divisions

\begin{tabular}{lllllrr}
\hline Variable & Period & \multicolumn{1}{l}{ I } & \multicolumn{1}{l}{ II } & \multicolumn{1}{l}{ III } & \multicolumn{1}{l}{ IV } & \multicolumn{1}{l}{ V } \\
\hline Cr_T $T_{\text {a }}$ & $1960-1990$ & -0.22 & 0.13 & $\mathbf{0 . 5 7}$ & -0.12 & 0.11 \\
& $1991-2013$ & $\mathbf{2 . 9 1}$ & 1.99 & 1.54 & 2.40 & 1.36 \\
Cr_R $R_{\text {s }}$ & $1960-1990$ & $-\mathbf{0 . 6 6}$ & -0.33 & -0.07 & -0.23 & -0.23 \\
& $1991-2013$ & $\mathbf{- 0 . 7 0}$ & -0.21 & -0.24 & -0.05 & 0.06 \\
Cr_VP & $1960-1990$ & $-\mathbf{1 . 0 4}$ & -0.07 & 0.56 & -0.17 & -0.11 \\
& $1991-2013$ & -0.06 & -0.20 & $\mathbf{0 . 5 8}$ & -0.04 & 0.13 \\
Cr_U2 & $1960-1990$ & -1.05 & -0.79 & -1.23 & $-\mathbf{1 . 5 4}$ & -0.83 \\
& $1991-2013$ & -1.13 & -0.52 & $-\mathbf{3 . 8 0}$ & 1.30 & -0.50 \\
\hline
\end{tabular}

The bold value indicates the dominant region for each climate factor's contribution

second division $\left(-0.2 \mathrm{~mm} \mathrm{year}^{-2}\right)$, the other regions all showed an increase in $\mathrm{ET}_{0}$ (Fig. 5C2; Table 6). Wind speed contributed from -1.23 (Fig. 5D1; Table 6) to $-3.8 \mathrm{~mm}$ year $^{-2}$ (Fig. 5D2; Table 6) to the $\mathrm{ET}_{0}$ trend the in the third division during both periods. However, the forth division's contribution to $\mathrm{ET}_{0}$ trend changed from negative to positive $\left(-1.54\right.$ and $1.30 \mathrm{~mm}_{\text {year }}{ }^{-2}$, respectively) and from the dominant to a non-dominant region.

In summary, for the dominant regional contributions, temperature changed from the third to the first division, radiation did not change, vapor pressure changed from the first to the fourth and the wind speed changed from the fourth to the third.

\section{Discussion}

\section{Evaporation paradox}

The "evaporation paradox" attracted the attention of many researchers since it was put forward (Brutsaert and Parlange 1998; Peterson et al. 1995; Roderick and Farquhar 
2002). However, some researchers reported that an increasing trend in $\mathrm{ET}_{0}$ recently appeared in China (Cong et al. 2010) and Australia (Gifford et al. 2005). _ENREF_20_ENREF_17ET 0 showed an increasing trend since 1992 in China from 1960 to 2007 (Liu et al. 2011a). In addition, $\mathrm{ET}_{0}$ also showed an increasing trend in the Songhua River basin $(3.775 \mathrm{~mm} /$ decade) and the Yellow River basin (1.092 mm/decade) from 1960 to 2007, which meant that the evaporation paradox disappeared. However, other researchers (Liu and Zeng 2004) argued that there was a decreasing trend in pan evaporation from 1961 to 2000 over the Yellow River basin. Our study indicated the $\mathrm{ET}_{0}$ increased at $2.8 \mathrm{~mm} /$ decade (Table 2) in the Loess Plateau (also in the middle Yellow River, Fig. 1). Consequently, we can conclude the "evaporation paradox" has currently disappeared in the Loess Plateau. The disappearance of the evaporation paradox may be due to climate change in the future (Zhang et al. 2013).

\section{Climate factors trend}

Changes in climatic factors have been documented in many studies over the past decade (Liu et al. 2012a; Liu and Zhang 2013; Zhao et al. 2014). The variation, statistical information and Pearson correlation (PC) of $\mathrm{ET}_{0}$ of the four climatic factors for the three periods were also investigated (Fig. 6; Tables 7, 8). The results showed that all the climatic factors had significant differences ( $p<0.01$ ) between 1960-1990 and 1991-2013, which indicated that the factors changed abruptly at approximately 1990 and caused an abrupt change in $\mathrm{ET}_{0}$ at the same time.

The increasing trend of temperature was slightly lower than the result of national research for the two sub-periods (0.009 vs. 0.011 and 0.032 vs. $0.050 \mathrm{~mm} \mathrm{year}^{-2}$ ) (Zhang et al. 2013), therefore the contributions were also lower than the national value (0.06 vs. 0.14 and 1.94 vs. 2.99). The temperature increased non-significantly $(p>0.05)$ for the two sub-periods, while it increased significantly $(p<0.001)$ at a rate of $0.0335^{\circ} \mathrm{C}$ year $^{-1}$ (Fig. 6a; Table 7) during 1960-2013 and became the predominant factor in the $\mathrm{ET}_{0}$ trend after 1990. In addition, the $T_{\mathrm{a}}$ and $\mathrm{ET}_{0}$ also did not show significant correlations during 1960-1990 ( $p>0.05, \quad \mathrm{PC}=0.35 ;$ Table 8$)$, while $T_{\mathrm{a}}$ became significant after $1990(p<0.01 ; \mathrm{PC}=0.62)$, indicating the $T_{\mathrm{a}}$ had a greater impact on the $\mathrm{ET}_{0}$ after 1990 than before.

Variations in solar radiation incident at earth's surface have profoundly affected the human and terrestrial environment. Various studies have documented that solar radiation at the surface has changed significantly on a decadal time scale (Gilgen et al. 2009; Krüger and Graß1 2002; You et al. 2010). In our study, radiation showed a significant decrease from 1960 to 1990 at a rate of $-0.0091 \mathrm{MJ} \mathrm{m}^{-2} \mathrm{day}^{-1} \operatorname{year}^{-1}(p<0.01$, Table 7), and an increase from 1991 to 2002 of $0.012 \mathrm{MJ} \mathrm{m}^{-2}$ day $^{-1}$ year $^{-1}$, which was consistent with Wild et al. (2005). Some researchers argued that the reversible phenomenon of radiation, also known as "from dimming to brightening", is explainable by cloudiness, atmospheric transmission and aerosol emissions (Krüger and Graß1 2002; Wild 2009; Wild et al. 2005). However, radiation showed decreasing trend again from 2002 to 2013 of $-0.0112 \mathrm{MJ} \mathrm{m}^{-2}$ day $^{-1}$ year $^{-1}$, which caused the decrease trend of $-0.0049 \mathrm{MJ} \mathrm{m}^{-2}$ day $^{-1}$ year $^{-1}$ from 1991 to 2013, and a similar result was also apparent over all of China (Zhang et al. 2013). Whether or not the radiation in China, or worldwide, reversed "from brightening to dimming" again requires further analysis of a longer series of observational data. Although variation in radiation was used to explain the change in $\mathrm{ET}_{0}(\mathrm{~Pa}-$ paioannou et al. 2011; Wang et al. 2007) and had a significant correlation with $\mathrm{ET}_{0}$ (Table 8), the change in solar radiation was not the predominant factor controlling the changes in $\mathrm{ET}_{0}$ in the Loess Plateau.

A change in wind speed could affect hydrological characteristics (Ishak et al. 2013) and the atmospheric evaporative demand calculation (McVicar et al. 2012). The wind speed significantly decreased $(p<0.01$, Table 7$)$ from 1960 to 1990 and highly influenced the decreasing $\mathrm{ET}_{0}$. In addition, the wind speed continued to decrease from 1991 to 2013, a phenomenon known as "wind stilling" (Roderick et al. 2007). The decrease in amplitude was low after 1990 (1960-1990 vs. 1991-2013: -0.0083 vs. $-0.0078 \mathrm{~m} \mathrm{~s}^{-1}$ year $^{-1}$, respectively), which was similar to the results of national research (Guo et al. 2011) and different than those found for the northwest arid region of China after 2000 (Liu and Zhang 2013). In addition, although the correlation coefficient between wind and $\mathrm{ET}_{0}$ was poor $(\mathrm{PC}=0.26)$ for the period of 1960-2013 $(p>0.05), \quad$ it was $0.64 \quad(p<0.001 ;$ Table 8$)$ for 1960-1990, which is consistent with our results that the wind speed and radiation dominate the decrease of $\mathrm{ET}_{0}$ before 1990 (shown in Table 5). In 1991-2013, the correlation between wind speed and $\mathrm{ET}_{0}$ was poor again, and it was not the dominant factor controlling the $\mathrm{ET}_{0}$ trend. Reasons for the decrease in wind such as increasing land surface roughness (Vautard et al. 2010) and rapid urbanization (Guo et al. 2011) have been documented. The change in surface roughness could explain the wind decrease in the Loess Plateau because the Chinese government adopted a series of strategies to restore the ecosystem including the Natural Forest Conversation Program (Zhang et al. 2000) and Grain for Green Project (Bennett 2008; FAO 2010). Therefore, the abandonment of agricultural land and large-scale afforestation caused a 

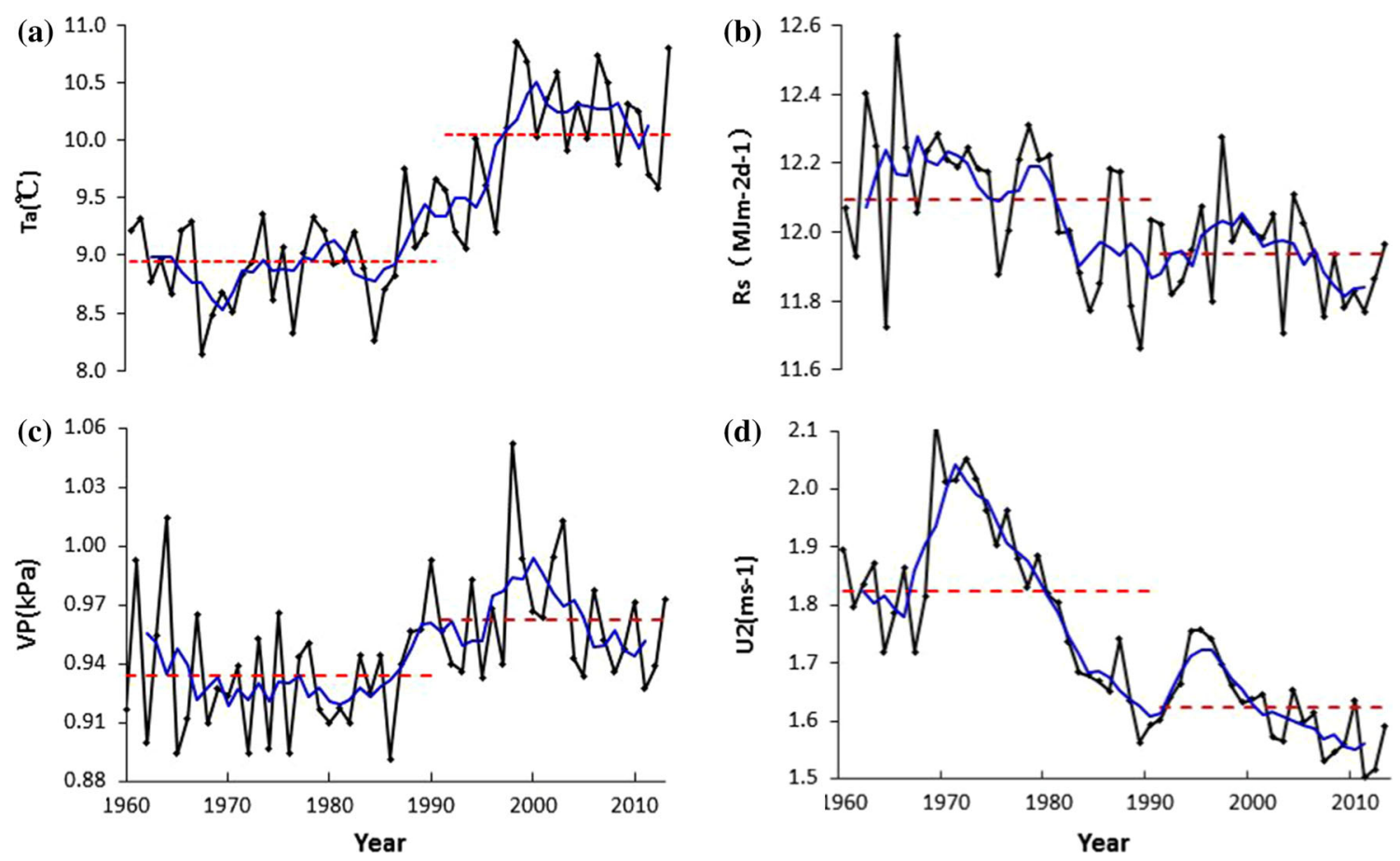

Fig. 6 Variations in temperature (a), solar radiation (b), vapor pressure (c), wind speed (d) for the Loess Plateau from 1960 to 2013. The blue line shows the 5 years moving average, and the red line is the average for the two sub-periods

Table 7 Characters of climate variables for the three periods in the Loess Plateau

\begin{tabular}{lllll}
\hline Variable & \multicolumn{1}{c}{$T_{\mathrm{a}}$} & \multicolumn{1}{l}{$R_{\mathrm{s}}$} & $\mathrm{VP}$ & $U 2$ \\
\hline Periods & & & & \\
1960-1990 & & & & \\
Mean & 8.95 & $12.1^{* *}$ & 0.93 & $1.82^{* * * *}$ \\
STD & 0.38 & 0.21 & 0.03 & 0.02 \\
Slope & 0.0086 & $-0.0091^{* *}$ & 0.0004 & $-0.0083^{* * * *}$ \\
1991-2013 & & & & \\
Mean & $10.05^{* * *}$ & 11.94 & $0.96^{* *}$ & 1.62 \\
STD & 0.53 & 0.14 & 0.03 & 0.01 \\
Slope & 0.0318 & -0.0049 & -0.0003 & $-0.0078^{* * *}$ \\
1960-2013 & & & & \\
Mean & 9.42 & 12.03 & 0.95 & 1.74 \\
STD & 0.71 & 0.20 & 0.03 & 0.15 \\
Slope & $0.0335^{* * *}$ & $-0.0071^{* * *}$ & $0.0008^{* *}$ & $-0.0075^{* * *}$ \\
\hline
\end{tabular}

The significant level of two sub-periods was indicated using the * upper-right of mean value. Slope is the line trend estimated by the linear regression. The slope unit of $T_{\mathrm{a}}, U 2, \mathrm{VP}$ and $R_{\mathrm{s}}$ is ${ }^{\circ} \mathrm{C}$ year ${ }^{-1}$, $\mathrm{m} \mathrm{s}^{-1}$ year $^{-1}$, $\mathrm{kPa}$ year $^{-1}$ and $\mathrm{MJ} \mathrm{m}{ }^{-2} \mathrm{day}^{-1} \mathrm{year}^{-1}$. $* p<0.05$; $* * p<0.01 ; * * * p<0.001$

higher amount of vegetation cover and a rapid increase in the land surface roughness, finally resulting in a decrease in wind speed.
Table 8 Pearson correlation between $\mathrm{ET}_{0}$ and the climatic variable for the three periods

\begin{tabular}{lllll}
\hline Variable & $T_{\mathrm{a}}$ & $R_{\mathrm{s}}$ & $\mathrm{VP}$ & $U 2$ \\
\hline Periods & & & & \\
$1960-1990$ & 0.35 & $0.81^{* * *}$ & $-0.64 * * *$ & $0.64 * * *$ \\
$1991-2013$ & $0.62 * *$ & $0.75^{* * *}$ & -0.08 & 0.19 \\
$1960-2013$ & $0.43^{* *}$ & $0.63^{* * *}$ & $-0.31 *$ & 0.26 \\
\hline
\end{tabular}

The significant level of three periods was indicated using the * upperright of Pearson correlation coefficient. Significant levels are indicated in one stars, two stars and three stars representing $p<0.05$, $p<0.01$ and $p<0.001$, respectively

An explanation for the pan evaporation or $\mathrm{ET}_{0}$ decrease is an increase in the evaporation from the environment surrounding the pan, i.e., the complementary relationship hypothesis (Brutsaert and Parlange 1998). If this hypothesis was applicable to the Loess Plateau, the actual evapotranspiration would increase and cause an increase in the actual vapor pressure. However, the vapor pressure did not show a significant increasing trend from 1960 to 1990 (Table 7), which indicated that the hypothesis was not applicable to that region. Although the vapor pressure dominant the pan evaporation trend in some regions (Cong et al. 2009), no significant trend was found in the two subperiods in the Loess Plateau, which effect could be neglected compared to others. 


\section{Uncertainties and suggestions}

Uncertainties in the $\mathrm{ET}_{0}$ trend and its contributing climatic factors exist in this analysis. First, even though cross validation was used to select the interpolation method of IDW to spatialize the variables, a spatial error was still present in our results (Tables 5, 6). Second, the various methods employed for detecting the changing point, such Cramer's (Zhang et al. 2013), Mann-Kendal and Pettitt test (Liu et al. 2011a), might have caused a difference in the changing point. Although a slight change was present approximately in 1975 and 1985 (Fig. 2a), Cramer's test did not detect the abrupt change, possibly due to the uncertainties of the method. Although we cannot precisely delineate a 'switch point' in the behavior, our analysis suggests that approximately 1990 was a transition time in which the $\mathrm{ET}_{0}$ trend began to increase. In addition, the variables in Eq. (5) should be independent so each factor represents a discrete contribution. VP instead of the vapor pressure deficit was considered because the vapor pressure deficit is the difference between VPs and VP, where VPs is a function of air temperature.

Despite the above uncertainties, this study confirmed the spatiotemporal variations in $\mathrm{ET}_{0}$ and also indicated the dominant factors in the two time series as reported in many previous studies (Liu and Zhang 2013; Liu et al. 2011b; Zhang et al. 2013). Furthermore, we also recommend that more attention should be paid to actual evapotranspiration $\left(\mathrm{ET}_{\mathrm{a}}\right)$ (Vetter et al. 2012), especially in response to climate change and human activities. For example, we can acquire the spatiotemporal $\mathrm{ET}_{\mathrm{a}}$ for a particular region or basin with $\mathrm{ET}_{\mathrm{a}}$ products (Cai et al. 2014; $\mathrm{Li}$ et al. 2014b; Xue et al. 2013), or construct better $\mathrm{ET}_{\mathrm{a}}$ model for our own study area with more precise forcing datasets (Minderlein and Menzel 2015; Yin et al. 2013; Zhang et al. 2008b). Clearer knowledge of $\mathrm{ET}_{\mathrm{a}}$ will provide a better vehicle for a full understanding of reference evapotranspiration.

\section{Conclusions}

This study investigated the spatiotemporal variation of $\mathrm{ET}_{0}$, $\mathrm{ET}_{0}$ trends and the contribution of four climatic factors to $\mathrm{ET}_{0}$ trends across five different divisions of the Loess Plateau based on 108 national meteorological stations during 1960-2013. Because the Loess Plateau is characterized by complex zonal variations and a vulnerable ecosystem, this research provides valuable information about $\mathrm{ET}_{0}$ and its contributions to climatic factors on a regional scale. A changing point in the $\mathrm{ET}_{0}$ series was detected at approximately 1990 by Cramer's test. The $\mathrm{ET}_{0}$ and its trends differed substantially between 1960-1990 and 1991-2013 for the entire plateau, characterized by a decreasing trend in $\mathrm{ET}_{0}$ of
$-1.22 \mathrm{~mm} \mathrm{year}^{-1}$ from 1960 to 1990 and an increasing trend of $1.15 \mathrm{~mm} \mathrm{year}^{-1}$ afterwards. Specifically, the highest and lowest $\mathrm{ET}_{0}$ values of 993 and $821 \mathrm{~mm}$ year $^{-1}$ were found in the third and fifth divisions, respectively. In addition, the greatest $\mathrm{ET}_{0}$ decreasing and increasing trends for 1960-1990 and 1991-2013 were also found in the first and fourth divisions, respectively.

The contribution of each climate variable to the $\mathrm{ET}_{0}$ trends was analyzed by the differential equation method. From 1960 to 1990, a decrease in $U 2$ had a negative effect on $\mathrm{ET}_{0}$ of $-0.84 \mathrm{~mm}$ year ${ }^{-2}$, followed by $R_{\mathrm{S}}$ and $\mathrm{VP}$, which offset the positive effect of $T_{\mathrm{a}}$. However, an increasing $T_{\mathrm{a}}$ became the dominant factor controlling the variations in $\mathrm{ET}_{0}$ from 1991 to 2013. The spatiotemporal variation of the predominant contribution region to the $\mathrm{ET}_{0}$ trend was determined for the five divisions. The $T_{\mathrm{a}}$ dominant region changed from the third to the first division for 1960-1990 and 1991-2013, radiation did not change, vapor pressure changed from the first to the fourth and the wind speed changed from the fourth to the third.

Acknowledgments This research was financially supported by the Natural Science Foundation of China 41330529, 41501032 and 41301496.

\section{References}

Allen RG, Pereira LS, Raes D, Smith M (1998) Crop evapotranspiration-guidelines for computing crop water requirementsFAO Irrigation and drainage paper 56. FAO

Bennett MT (2008) China's sloping land conversion program: institutional innovation or business as usual? Ecol Econ 65(4):699-711. doi:10.1016/j.ecolecon.2007.09.017

Bormann H (2011) Sensitivity analysis of 18 different potential evapotranspiration models to observed climatic change at German climate stations. Clim Change 104(3-4):729-753. doi:10.1007/s10584-010-9869-7

Brutsaert W, Parlange M (1998) Hydrologic cycle explains the evaporation paradox. Nature 396:30. doi:10.1038/23845

Cai XT et al (2014) Assessment of simulated water balance from Noah, Noah-MP, CLM, and VIC over CONUS using the NLDAS test bed. J Geophys Res Atmos 119:13751-13770. doi:10.1002/2014JD022113

Chen SB, Liu YF, Axel T (2006) Climatic change on the Tibetan Plateau: potential evapotranspiration trends from 1961-2000. Clim Change 76(3-4):291-319

Cong Z, Yang D, Ni G (2009) Does evaporation paradox exist in China? Hydrol Earth Syst Sci 13(3):357

Cong ZT, Zhao JJ, Yang DW (2010) Understanding the hydrological trends of river basins in China. J Hydrol 388:350-356

Dai L et al (2013) The spatial variation of alpine timberlines and their biogeographical characteristics in the northern Tianshan Mountains of China. Environ Earth Sci 68(1):129-137. doi:10.1007/ s12665-012-1721-0

FAO (2010) Global forest resources assessment 2000 main report, 140. FAO Forestry Paper, Rome

Gao G, Chen DL, Ren GY, Chen Y, Liao YM (2006) Spatial and temporal variations and controlling factors of potential evapotranspiration in China: 1956-2000. J Geogr Sci 16(1):3-12 
Gifford RM, Farquhar GD, Roderick ML, Nicholls N (2005) Workshop summary on pan evaporation: An example of the detection and attribution of climate change variables. Australia Academy of Sciences, pp 22-23

Gilgen H, Roesch A, Wild M, Ohmura A (2009) Decadal changes in shortwave irradiance at the surface in the period from 1960 to 2000 estimated from Global Energy Balance Archive Data. J Geophys Res Atmos. doi:10.1029/2008JD011383

Golubev VS et al (2001) Evaporation changes over the contiguous US and the former USSR: a reassessment. Geophys Res Lett 28(13):2665-2668. doi:10.1029/2000GL012851

Guo H, Xu M, Hu Q (2011) Changes in near-surface wind speed in China: 1969-2005. Int J Climatol 31:349-358. doi:10.1002/joc. 2091

Heydari M, Tajamoli A, Ghoreishi S, Darbe-Esfahani M, Gilasi H (2014) Evaluation and calibration of Blaney-Criddle equation for estimating reference evapotranspiration in semiarid and arid regions. Environ Earth Sci. doi:10.1007/s12665-014-3809-1

Huang M, Zhang L, Gallichand J (2003) Runoff responses to afforestation in a watershed of the Loess Plateau, China. Hydrol Process 17(13):2599-2609. doi:10.1002/hyp.1281

Integrated Survey Team of Chinese Academy of Sciences (CAS) of the Loess Plateau (1992) Dataset of Resources, Environment and Society for the Loess Plateau Region (in Chinese). China Economic Publishing House, Beijing

IPCC (2013) Summary for Policymakes: The Physical Science Basis, Contribution of Working Group I to the IPCC Fifth Assessment Report Climate Change

Ishak AM, Remesan R, Srivastava PK, Islam T, Han D (2013) Error correction modelling of wind speed through hydro-meteorological parameters and mesoscale model: a hybrid approach. Water Resour Manag 27(1):1-23

Jhajharia D, Dinpashoh Y, Kahya E, Singh VP, Fakheri-Fard A (2012) Trends in reference evapotranspiration in the humid region of northeast India. Hydrol Process 26(3):421-435. doi:10. 1002/hyp. 8140

Jinbai H, Jiawei W, Osamu H, Hiroshi Y (2014) Runoff and water budget of the Liudaogou Catchment at the wind-water erosion crisscross region on the Loess Plateau of China. Environ Earth Sci 72(9):3623-3633. doi:10.1007/s12665-014-3273-y

Jung $M$ et al (2010) Recent decline in the global land evapotranspiration trend due to limited moisture supply. Nature 467(7318):951-954

Kendall MG (1948) Rank correlation methods. Griffin, Oxford, England

Krüger O, Graß1 H (2002) The indirect aerosol effect over Europe. Geophys Res Lett 29(19):31-1-31-4. doi:10.1029/2001GL014081

Li Z, Zheng F, Liu W, Flanagan DC (2010) Spatial distribution and temporal trends of extreme temperature and precipitation events on the Loess Plateau of China during 1961-2007. Quatern Int 226: 92-100. doi:10.1016/j.quaint.2010.03.003

Li Z, Zheng F, Liu W (2012) Spatiotemporal characteristics of reference evapotranspiration during 1961-2009 and its projected changes during 2011-2099 on the Loess Plateau of China. Agric For Meteorol 154-155:147-155. doi:10.1016/j.agrformet.2011. 10.019

Li X, Liu L, Duan Z, Wang N (2014a) Spatio-temporal variability in remotely sensed surface soil moisture and its relationship with precipitation and evapotranspiration during the growing season in the Loess Plateau, China. Environ Earth Sci 71(4):1809-1820. doi:10.1007/s12665-013-2585-7

Li XP, Wang L, Chen DL, Yang K, Wang AH (2014b) Seasonal evapotranspiration changes (1983-2006) of four large basins on the Tibetan Plateau. J Geophys Res Atmos 119:13079-13095. doi:10.1002/2014JD022380
Liu C, Zeng Y (2004) Changes of pan evaporation in the recent 40 years in the Yellow River Basin. Water Int 29(4):510-516

Liu X, Zhang D (2013) Trend analysis of reference evapotranspiration in Northwest China: the roles of changing wind speed and surface air temperature. Hydrol Process 27(26):3941-3948. doi:10.1002/hyp.9527

Liu M, Shen Y, Zeng Y, Liu C (2010a) Trend in pan evaporation and its attribution over the past 50 years in China. J Geogr Sci 20(4):557-568

Liu Q, Yang Z, Cui B, Sun T (2010b) The temporal trends of reference evapotranspiration and its sensitivity to key meteorological variables in the Yellow River Basin, China. Hydrol Process 24(15):2171-2181. doi:10.1002/hyp.7649

Liu X, Luo Y, Zhang D, Zhang M, Liu C (2011a) Recent changes in pan-evaporation dynamics in China. Geophys Res Lett. doi:10. 1029/2011GL047929

Liu X, Zheng H, Zhang M, Liu C (2011b) Identification of dominant climate factor for pan evaporation trend in the Tibetan Plateau. J Geogr Sci 21(4):594-608. doi:10.1007/s11442-011-0866-1

Liu X, Liu C, Luo Y, Zhang M, Xia J (2012a) Dramatic decrease in streamflow from the headwater source in the central route of China's water diversion project: Climatic variation or human influence? J Geophys Res Atmos. doi:10.1029/2011JD016879

Liu C, Zhang D, Liu X, Zhao C (2012b) Spatial and temporal change in the potential evapotranspiration sensitivity to meteorological factors in China (1960-2007). J Geogr Sci 22(1):3-14. doi:10. 1007/s11442-012-0907-4

Liu X, Liu W, Xia J (2013) Comparison of the streamflow sensitivity to aridity index between the Danjiangkou Reservoir basin and Miyun Reservoir basin, China. Theor Appl Climatol 111(3-4):683-691. doi:10.1007/s00704-012-0701-3

Lloyd CD (2005) Assessing the effect of integrating elevation data into the estimation of monthly precipitation in Great Britain. J Hydrol 308(1-4):128-150. doi:10.1016/j.jhydrol.2004.10.026

Lu GY, Wong DW (2008) An adaptive inverse-distance weighting spatial interpolation technique. Comput Geosci UK 34(9):1044-1055

McVicar TR et al (2007) Spatially distributing monthly reference evapotranspiration and pan evaporation considering topographic influences. J Hydrol 338(3):196-220

McVicar TR et al (2012) Global review and synthesis of trends in observed terrestrial near-surface wind speeds: implications for evaporation. J Hydrol 416(3):182-205

Meng D, Mo X (2012) Assessing the effect of climate change on mean annual runoff in the Songhua River basin, China. Hydrol Process 26(7):1050-1061. doi:10.1002/hyp.8180

Minderlein S, Menzel L (2015) Evapotranspiration and energy balance dynamics of a semi-arid mountainous steppe and shrubland site in Northern Mongolia. Environ Earth Sci 73(2):593-609. doi:10.1007/s12665-014-3335-1

New M, Hulme M, Jones P (2000) Representing twentieth-century space-time climate variability. Part II: development of 1901-96 monthly grids of terrestrial surface climate. J Clim 13(13):2217-2238

Papaioannou G, Kitsara G, Athanasatos S (2011) Impact of global dimming and brightening on reference evapotranspiration in Greece. J Geophys Res Atmos 116(D9):D09107. doi:10.1029/ 2010JD015525

Peterson TC, Golubev VS, Groisman PY (1995) Evaporation losing its strength. Nature 377(6551):687-688

Qian T, Dai A, Trenberth KE, Oleson KW (2006) Simulation of global land surface conditions from 1948 to 2004. Part I: forcing data and evaluations. J Hydrometeorol 7(5):953-975. doi:10. 1175/JHM540.1 
Roderick ML, Farquhar GD (2002) The cause of decreased pan evaporation over the past 50 years. Science 298(5597):1410-1411. doi:10.1126/science.1075390-a

Roderick ML, Farquhar GD (2005) Changes in New Zealand pan evaporation since the 1970s. Int J Climatol 25(15):2031-2039. doi:10.1002/joc. 1262

Roderick ML, Rotstayn LD, Farquhar GD, Hobbins MT (2007) On the attribution of changing pan evaporation. Geophys Res Lett 34(17):251-270

Sentelhas PC, Gillespie TJ, Santos EA (2010) Evaluation of FAO Penman-Monteith and alternative methods for estimating reference evapotranspiration with missing data in Southern Ontario, Canada. Agric Water Manag 97(5):635-644. doi:10.1016/j. agwat.2009.12.001

Srivastava PK, Han D, Rico Ramirez MA, Islam T (2013) Comparative assessment of evapotranspiration derived from NCEP and ECMWF global datasets through weather research and forecasting model. AtScL 14(2):118-125. doi:10.1002/asl2.427

Srivastava PK, Han D, Rico-Ramirez MA, Islam T (2014) Sensitivity and uncertainty analysis of mesoscale model downscaled hydrometeorological variables for discharge prediction. Hydrol Process 28(15):4419-4432. doi:10.1002/hyp.9946

Srivastava PK et al (2015a) Seasonal evaluation of evapotranspiration fluxes from MODIS satellite and mesoscale model downscaled global reanalysis datasets. Theor Appl Climatol:1-13. doi:10. 1007/s00704-015-1430-1

Srivastava PK, Islam T, Gupta M, Petropoulos G, Dai Q (2015b) WRF dynamical downscaling and bias correction Schemes for NCEP estimated hydro-meteorological variables. Water Resour Manag 29(7):2267-2284

Tabari H, Marofi S, Aeini A, Talaee PH, Mohammadi K (2011) Trend analysis of reference evapotranspiration in the western half of Iran. Agric For Meteorol 151(2):128-136

Tang B, Tong L, Kang S, Zhang L (2011) Impacts of climate variability on reference evapotranspiration over 58 years in the Haihe river basin of north China. Agric Water Manag 98(10): $1660-1670$

TÜRkeŞ M (1996) Spatial and temporal analysis of annual rainfall variations in Turkey. Int J Climatol 16(9):1057-1076

Vautard R, Cattiaux J, Yiou P, Thepaut JN, Ciais P (2010) Northern Hemisphere atmospheric stilling partly attributed to an increase in surface roughness. Nat Geosci 3(11):756-761

Vetter S, Schaffrath D, Bernhofer C (2012) Spatial simulation of evapotranspiration of semi-arid Inner Mongolian grassland based on MODIS and eddy covariance data. Environ Earth Sci 65(5):1567-1574. doi:10.1007/s12665-011-1187-5

Wan H, Wang XL, Swail VR (2010) Homogenization and trend analysis of Canadian near-surface wind speeds. J Clim 23(5):1209-1225

Wang Y, Jiang T, Bothe O, Fraedrich K (2007) Changes of pan evaporation and reference evapotranspiration in the Yangtze River basin. Theor Appl Climatol 90(1):13-23

Wang QX, Fan XH, Wang MB (2011) Precipitation trends during 1961-2010 in the Loess Plateau region of China (in chinese). Acta Ecol Sin 31(19):5512-5523

Wang Qx, Fan Xh, Qin Zd, Wang Mb (2012) Change trends of temperature and precipitation in the Loess Plateau Region of China, 1961-2010. Glob Planet Change 92(4):138-147

Wild M (2009) Global dimming and brightening: a review. J Geophys Res Atmos 114:D00D16. doi:10.1029/2008JD011470
Wild $\mathrm{M}$ et al (2005) From dimming to brightening: decadal changes in surface solar radiation. Science 308:847-850. doi:10.1126/ science. 1103215

WMO (1996) Guide to meteorological instruments and methods of observation, 6th edn. WMO Rep. 8. World Meteorological Organization: Geneva

Wu Q, Yang W (1998) Forest and grassland vegetation construction and its sustainable development in Loess Plateau. China's Science Press, Beijing

Xu C, Gong L, Jiang T, Chen D, Singh V (2006) Analysis of spatial distribution and temporal trend of reference evapotranspiration and pan evaporation in Changjiang (Yangtze River) catchment. J Hydrol 327(1):81-93

Xue Bl et al (2013) Evaluation of evapotranspiration estimates for two river basins on the Tibetan Plateau by a water balance method. J Hydrol 492(2013):290-297

Yin Y, Wu S, Zhao D (2013) Past and future spatiotemporal changes in evapotranspiration and effective moisture on the Tibetan Plateau. J Geophys Res Atmos. doi:10.1002/jgrd.50858

You Q et al (2010) From brightening to dimming in sunshine duration over the eastern and central Tibetan Plateau (1961-2005). Theor Appl Climatol 101(3-4):445-457. doi:10.1007/s00704-0090231-9

Zeng Y, Qiu X, Pan A, Liu C (2008) Distributed modeling of global solar radiation over rugged terrain of the Yellow River Basin (in Chinese). Adv Earth Sci 23(11):1185-1193

Zhang $\mathrm{P}$ et al (2000) China's forest policy for the 21 st century. Science 288(5474):2135-2136

Zhang Y, Liu C, Tang Y, Yang Y (2007a) Trends in pan evaporation and reference and actual evapotranspiration across the Tibetan Plateau. J Geophys Res Atmos. doi:10.1029/2006JD008161

Zhang X et al (2007b) Modelling the impact of afforestation on average streamflow in the Loess Plateau, China. Hydrol Process 22:1996-2004. doi:10.1002/hyp.6784

Zhang Y, Chiew FHS, Zhang L, Leuning R, Cleugh HA (2008a) Estimating catchment evaporation and runoff using MODIS leaf area index and the Penman-Monteith equation. Water Resour Res 44(10):W10420. doi:10.1029/2007WR006563

Zhang X, Zhang L, Zhao J, Rustomji P, Hairsine P (2008b) Responses of streamflow to changes in climate and land use/cover in the Loess Plateau. Water Resour Res, China. doi:10.1029/ 2007WR006711

Zhang D, Liu X, Hong H (2013) Assessing the effect of climate change on reference evapotranspiration in China. Stoch Env Res Risk A 27(8):1871-1881. doi:10.1007/s00477-013-0723-0

Zhang D, Hong H, Zhang Q, Nie R (2014) Effects of climatic variation on pan-evaporation in the Poyang Lake Basin, China. Clim Res 61(1):29-40. doi:10.3354/cr01225

Zhao Y et al (2014) Spatio-temporal variation of reference evapotranspiration and aridity index in the Loess Plateau Region of China, during 1961-2012. Quatern Int 349:196-206. doi:10. 1016/j.quaint.2014.06.050

Zheng H, Liu X, Liu C, Dai X, Zhu R (2009) Assessing contributions to panevaporation trends in Haihe River Basin,China. J Geophys Res Atmos 114(D24):D24105. doi:10.1029/2009JD012203

Zuo D, Xu Z, Yang H, Liu X (2012) Spatiotemporal variations and abrupt changes of potential evapotranspiration and its sensitivity to key meteorological variables in the Wei River basin, China. Hydrol Process 26(8):1149-1160 